\section{Questión}

Periodismo / Comunicación ISSN 1669-6581
- Av. $44 \mathrm{~N}^{\circ} 676,1^{\circ}$ piso

CP 1900 - La Plata - Argentina

www.perio.unlp.edu.ar/question

Radios Universitarias españolas y pandemia. Entrevista sonora al Dr. Daniel Martín-Pena

Mag. Carlos Milito

DOI: https://doi.org/10.24215/16696581e327

\title{
Radios Universitarias españolas y pandemia
}

Entrevista sonora al Dr. Daniel Martín-Pena

\section{Spanish University Radios and Pandemic}

Sound interview with Dr. Daniel Martín-Pena

Mag. Carlos Milito / carlosmilito2@gmail.com Carlos Milito (La Plata, 1960) es Magister en planificación y gestión de procesos comunicacionales, Docente Universitario y Director de la Especialización en Comunicación Radiofónica y fue Coordinador de RadioPerio, radio web funciones que ejerce y ejerció en la FPyCS-UNLP. Fue Director de Radio Provincia de Buenos Aires y ahora coordina la 1894Radioonline de Villa Elisa. Locutor Nacional y Periodista.

Daniel Martín-Pena es Doctor en Comunicación por la Universidad de Huelva (España) y Máster en Comunicación y Educación Audiovisual por esa misma Universidad. Licenciado en Comunicación Audiovisual por la Universidad de Extremadura (España).

Profesor acreditado Contratado Doctor de la Universidad de Extremadura. Impartiendo docencia a tiempo completo en los grados de Comunicación Audiovisual, Periodismo e Información y Documentación.

Director de OndaCampus RadioTv de la UEx desde su creación en 2004. Presidente de la Asociación de Radios Universitarias de España (ARU) y Presidente de RIU (Radio Internacional Universitarias, Red de Redes). Ha impartido conferencias sobre el fenómeno de las radios universitarias en Italia, Francia, Portugal, Argentina, México, Costa Rica, Paraguay y Colombia realizando estancias de investigación en varias universidades latinoamericanas. Ha sido editor de los libros: "Las radios universitarias en América y Europa" y "Las radios universitarias, más allá de la radio: las TIC como recursos de interacción radiofónica. Además 
coautor de varios que son referente en la materia de la radio y la divulgación de la ciencia: "La radio universitaria. Gestión de la información, análisis y modelos de organización" (2016), "La divulgación científica Estructuras y prácticas en las universidades" (2017) y "Divulgación científica y función social en las universidades" (2018). Codirector de varios trabajos Fin de Grado y de tesis en producción, así como miembro de tribunal de varias tesis relacionadas con el fenómeno de las radios universitarias.

\section{Entrevista completa:}

https://ar.ivoox.com/es/51074930 